\title{
BUSINESS INTELLIGENCE IN THE CLOUD
}

Authors:

Willem J.J. Thompson ${ }^{1}$

Jakobus S. van der Walt

\section{Affiliations:}

${ }^{1}$ Department of Information

Technology, Tswhane

University of Technology,

South Africa

\section{Correspondence to:}

Willem Thompson

email:

wimpie.thompson@gmail.com

Postal address:

PO Box 38948, Faerie Glen,

Pretoria 0043

\section{Keywords:}

Business intelligence; BI;

cloud computing; software as

a service; SaaS

Dates:

Received: 21 July 2010

Accepted: 11 Nov. 2010

Published: 07 Dec. 2010

How to cite this article: Thompson, W.J.J. \& Van der Walt, J.S., 2010, 'Business intelligence in the cloud', SA Journal of Information Management 12(1), Art. \#445, 5 pages. DOI: $10.4102 /$ sajim. v12i1.445

This article is available at:

http:/ / www.sajim.co.za

(c) 2010. The Authors. Licensee: OpenJournals Publishing. This work is licensed under the Creative Commons Attribution License.

\section{ABSTRACT}

Cloud computing has become an important topic to research because of the value it can provide to the business. In this article, the researcher examined how Business Intelligence (BI) can be offered to the business over the Internet as a solution. BI environments, however, require a large capital layout to implement and support the large volumes of data that needs to be analysed to identify trends. It also requires enormous processing power which places pressure on the business resources. The goal of this article is to show how BI will be offered as a Software as a Service (SaaS) solution to the business. The BI SaaS solution will allow companies to reduce cost of having a BI solution and also having access to the latest software which will give the business an edge on their competition. By making use of a literature review the researcher were able gather and present evidence to support the value that the BI SaaS solution will add to the business and how such a BI SaaS solution will look like. As part of this research paper the researcher will also identify the challenges that the business will face when making us a BI SaaS solution.

\section{INTRODUCTION}

Having knowledge about the business environment is key for keeping the business profitable and competitive in today's business environment. By having the right insight into your environment, you will be able to take the necessary actions to address trends in the market and allowing you to identify opportunities quickly and get the most of it. To make sure that businesses have knowledge about its environment, it is beneficial to make use of Business Intelligence (BI) to produce and process information about the environment for strategic purposes.

For businesses to have better insight into their operations it is important to apply data analysis techniques on their information to drive decisions and actions. This will allow them to set the right strategy to achieve increased sales, identify issues and to become a dynamic business that can meet today's challenges of fast delivery.

Processing large amounts of data in the data warehouse requires enormous processing power and space. These resources are key for businesses to run its daily operations and information technology (IT) departments cannot provide additional processing power to the data warehouse until after hours. In this case cloud computing can be used successfully to provide scalability for peak periods when needed and only pay for what is used.

The purpose of our research was to investigate how cloud computing could be used to provide a BI Software as a Service (SaaS) solution to the business. In this article, the researcher will be answering the following questions:

- How does the BI SaaS look and work?

- Which BI vendors provide this service over the Internet?

- What are the advantages that businesses will receive when making use of BI SaaS solution?

- What are the challenges faced when making use of a BI SaaS solution?

\section{HAVING THE RIGHT INSIGHT IN BUSINESS}

BI provides businesses with a solution to combine and analyse data sources and derive valuable information from this data, providing key insights and data points used to make informed and intelligent business decisions. These solutions include data warehousing, data mining and trend analysis systems (Bell \& Todd 2007).

Profit and performance of a business is improved by making use of BI to organise key information to be able to make decisions and take actions. BI combines products, technology and methods which assist in improving business performance which increases revenues and/or reduce costs (Williams \& Williams 2007).

One of the greatest gaps that companies are facing today is how to effectively manage information. Nine out of ten executives of large US companies believe they need stronger information management capabilities to thrive and grow (Chisholm \& Human 2006). By implementing BI solutions, the business has the capability to access new data to better inform management decisions. This translates into cost savings to the business because organisational recourses are more effectively allocated (Chisholm \& Human 2006).

In order to see how BI can benefit the business the researcher will have a look at the following example of how BI improved the logistics management of businesses where these businesses have faced increased complexity in managing their logistics. This increased complexity in logistics management has led many companies to outsource their logistics activities to Third Party Logistics (3PL) providers. 
To effectively manage the supply chains of their customers, 3PLs are using BI tools, like data warehousing and Online Analytical Processing (OLAP), to constantly analyse data collected from various sources and convert it into actionable information. By providing a unified view of the supply chain, these tools help 3P to improve services like transportation management, warehousing and inventory management and thereby provide clients with information specific to their supply chain, increasing the client's market responsiveness (Chung, Chen, \& Jay 2002).

By making use of $\mathrm{BI}$, companies are able to retain profitable customers and attract others like them, by creating marketing programs that reflect each customer's uniqueness and preferences. BI also allows companies to monitor changes in behaviour of customers that could trigger specific actions and this provides companies with the opportunity to increase sales per customer by predicting which are most likely to buy a certain product. This is done by adjusting pricing strategies to counter competition and maximise profitability and proactively monitor, diagnose and predict customer service requirements instead of waiting for breakages or outages to occur at the customer's site. BI allows the business to allocate limited resources for optimal advantage, including budget, staff and IT systems (Maini 2010:6).

Companies are facing the following challenges when making use of BI (LaValle 2009:3):

- A pressing need exists for companies to reduce capital expenditure and operational cost.

- There is a shortage of skills to effectively create and maintain a business analytics solution that adds value to the business.

- The businesses of today generate large volumes of data from all different data sources, including enterprise resource planning (ERP) systems, customer relationship management (CRM) solutions, Global Positioning System (GPS) logs and tweets.

- The velocity with which data is generated is enormous and arrives on a daily, hourly and real-time basis. This requires powerful machines to process the data to identify trends in the data and can sometimes only be executed in the evening not to effect the business during working hours.

- The business requires an on-demand solution for sales analysis, supply chain visibility, customer analytics, merchandising and product analysis.

- In order to control infrastructure costs can be an enormous task to ensure that the appropriate infrastructure is available for peak times.

- The cost for implementing and maintaining a business analytics solution is expensive.

BI offers businesses a solution to analyse their data and allows them to make informed business decisions to improve the profit and performance of the business. However, BI is expensive to implement and maintain and also requires powerful infrastructure which is sometimes only available after hours. The recession brought a pressing need for businesses to reduce cost but still have the right technology in place to allow them to make decisions that allows them to identify opportunities and proactively identify risks that can affect the business. This is where cloud computing can offer businesses a solution to reduce cost but still have access to best of breed solutions.

\section{USING THE CLOUD TO ACHIEVE BUSINESS AGILITY}

Cloud Computing provides IT capabilities to companies via the Internet which is dynamically scalable from third party vendors. Cloud Computing is driven by economies of scale in which there is a pool of virtualised and dynamically-scalable computing power, providing storage, platforms and services on demand to external customers via the Internet. This represents a new paradigm for companies' IT operations where a pay-as-you-go business model will be used to procure, deliver and support

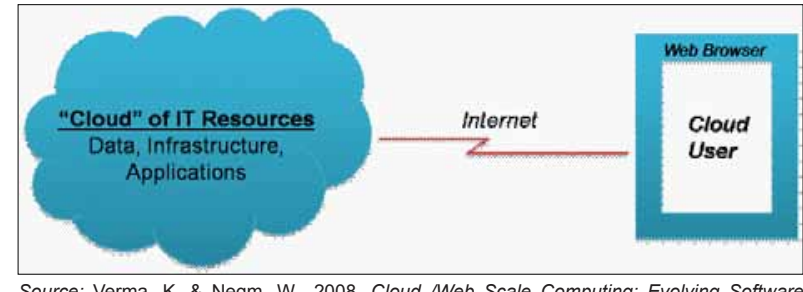

Source: Verma, K. \& Negm, W., 2008, Cloud Web Scale Computing: Evolving Softwar Architectures. Accenture Technology Vision, viewed 27 April 2008, from http://www.accenture. com/cloud/

\section{FIGURE 1}

Cloud computing

infrastructure, platform, application and business processes capabilities. Companies need not have knowledge of, expertise in, or control over the technology infrastructure in the cloud that supports them (Foster, Zhao, Raicu \& Lu 2008).

Cloud computing consists of four layers of which Industry Clouds are the top layer of the stack as seen in the diagram below. Industry Clouds are externally provisioned service for managing a business process that is Internet-enabled. Examples of these services include claims processing, expense management or procurement and the processes are typically priced on a pertransaction basis exist (Daugherty \& Raj 2008:4).

The next layer in the cloud computing stack is the Application Cloud (desktop and collaboration, SaaS). Application Clouds provide services from procurement to ERP systems and content management systems. These applications run on the third-party infrastructure and companies subscribe to these services based on the number of users or seats (Daugherty \& Raj 2008:4).

The third layer is the Platform Cloud which allows software vendors to develop and deploy online applications quickly, using the third-party infrastructure (Daugherty \& Raj 2008:5). The last layer in the cloud computing stack is the Infrastructure Cloud or Utility Computing which is where the cloud computing vendor provides 'raw' infrastructure, such as processing power, network bandwidth, storage and memory to companies on an on-demand basis (Daugherty \& Raj 2008:5).

Cloud computing is a construct that allows applications to be hosted on either a private or a public cloud. The software for these cloud applications are used out of the box as it is and minimum changes are required to get it working. The cloud provider does all the patching and upgrades as well as keeping the infrastructure running (Velte, Velte \& Elsenpeter 2010:10).

Applications can be hosted for a business by either making use of a dedicated server or a private or public cloud. A dedicated server is a server dedicated to running certain software applications (EduCause, 2009). All the resources for this server are only dedicated to a certain software application and cannot be shared to other applications if they, for example, require more processing power.

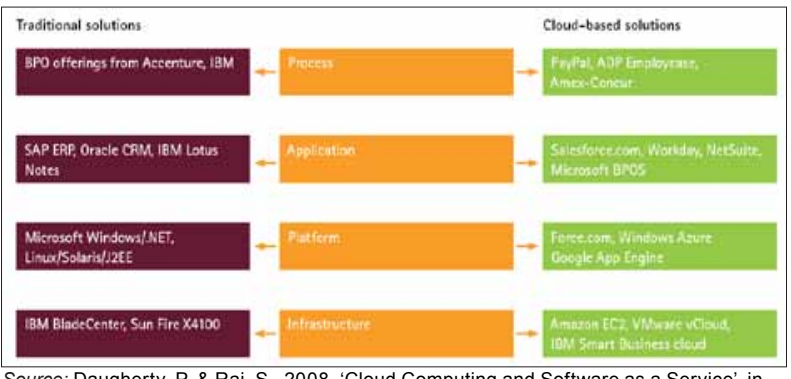

Source: Daugherty, P. \& Raj, S, 2008, 'Cloud Computing and Software as a Service', in Accenture, retrieved 29 April 2009, from http://www.accenture.com/cloud/

FIGURE 2

Cloud computing types 


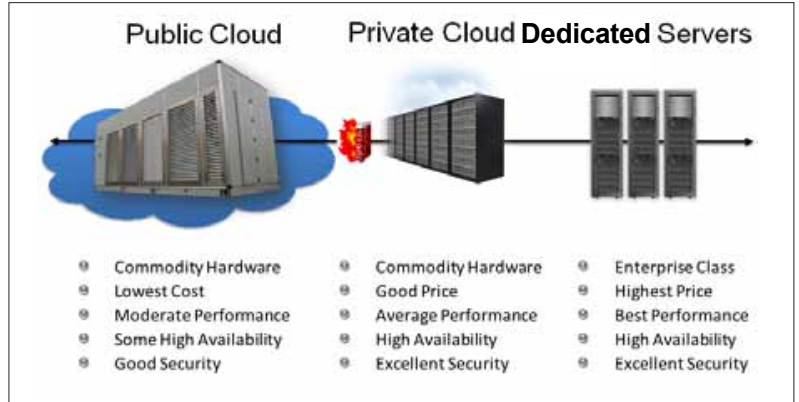

Source: Papaioannou, T. n.d., Cloud Computing and your Data Warehouse' in Teradata Labs, viewed 30 June 2010, from http://www.slideshare.net/drluckyspin/cloud-computing-and-yourdata-warehouse

FIGURE 3
The hybrid cloud

When a business moves to a Private Cloud it provides flexible power to the business making use of their own IT infrastructure. Demand for resources can be managed dynamically to meet the needs of the department computing power. The advantage of this is that it is behind the security of the business' firewall. This allows companies to make the most of their existing hardware and network infrastructure by building a Private Cloud (Ubuntu, n.d.)

The Public Cloud provides services which is accessible from anywhere in the world and allows businesses to scale the resources required for their computing needs dynamically when required. The Public Cloud infrastructure is owned and managed by a business that sells cloud services to the general public (Microsoft 2010).

Cloud-based services are available at all levels of the enterprise technology stack. Businesses will be free to evolve individual IT models, based strictly on business needs rather than on technology constraints. This new, adaptable IT framework could simplify managing cost, scale and agility. Cloud Computing will create a new wave of innovations in the cloud and an increased computing industrialisation of IT. These innovations will result in changes in business models and allow new levels of benefit for companies tapping into its power (Swaminathan, Daugherty \& Tobolski 2009).

\section{BUSINESS INTELLIGENCE ON DEMAND}

By making use of cloud computing, companies are able to solve the issues that they are experiencing with their current onsite BI solutions. Having an on-demand BI solution will allow companies to reduce their operation cost and make use of the solution on a subscription basis. This eliminates the need for going through long capital requests and the business is able to get access to the system immediately, allowing the IT department to accelerate the speed of value to the business.

The on-demand BI solution is delivered as a SaaS solution to the business. The software solution is delivered via the Web on an annual or monthly service fee, rather than an up-front purchase basis. This SaaS solution that is provided from a third party over the Internet can provide increased operational and financial flexibility and reduced maintenance and support of the technology.

Figure 4 shows how the BI solution will be defined in a cloud computing environment. On a daily basis, transactional data will be extracted from the client environment, transformed and loaded into the business cubes in the data warehouse.

The data warehouse and data mining tools in the cloud environment will be used to provide the business with the information and tools that they need to make both operational and strategic business decisions. The data warehouse gives the

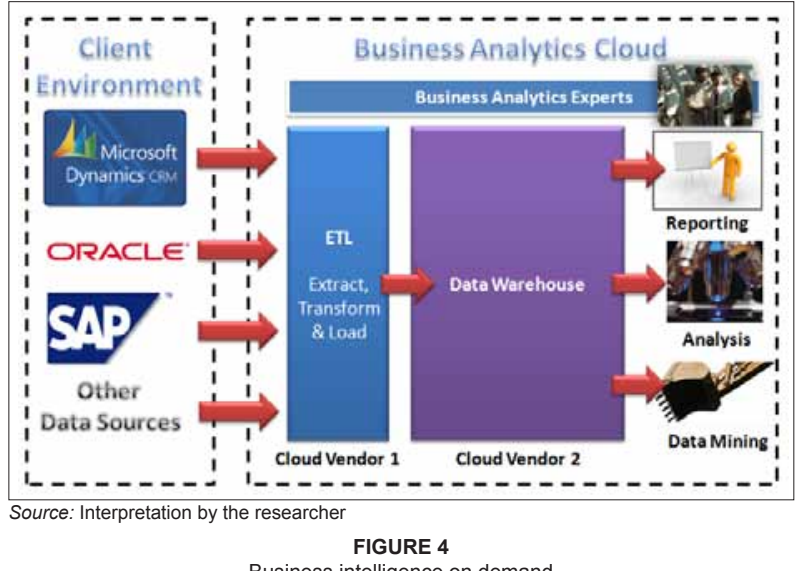

Business intelligence on demand

business the ability to study past behaviours and actions, in order to understand where the business has been, determine its current situation and predict or change what will happen in the future.

The BI software provides drilldown capabilities, which allows users to click on information in the report to find relevant details about a specific piece of data. The BI cloud solution will provide standard reports that can be used immediately when the business starts making use of the cloud solution. Commonly requested business reports can be published in a centralised, managed and secured environment, which can be accessed from any part in the world.

The OLAP engine in the BI cloud solution makes it quick and easy to perform ad-hoc queries and analysis of large amounts of complex data across all aspects of the business. This allows the business to improve reporting for sales, marketing, management reporting, business process management, budgeting and forecasting, financial reporting and similar areas.

An important feature of the BI cloud is the dashboard that provides an executive information view of the business that is designed to be easy to read. The dashboard consolidates all information into a single, easy-to-use interface that allows managers to proactively identify problem areas in the business and take the necessary action to correct negative trends. It provides a visual presentation of performance measures and gives the business the flexibility to make more informed decisions based on collected BI. The dashboard saves time by running multiple reports and allows the manager to gain total visibility of all aspects in the business instantly.

The cloud vendor is responsible for keeping the software up to date and because the software is hosted off-site, it also does not make use of the critical resources that influence the company's core business. Precious processing power and storage can be used to support the core business and what makes this model even more attractive is the fact that data analysis and mining algorithms can be executed any time of the day. The cloud solution is also accessible from anywhere in the world.

\section{IMPACT ON THE BUSINESS}

SaaS vendors like Panorama (Sullivan 2008) that brought analytics and reporting to Google created a SaaS BI solution that brings more robust OLAP, analytics and reporting, along with the cloud manner of low barrier-to-entry to their enterprise-class customers. Panorama also feels an advantage for companies that make use of BI SaaS solutions are the ability to implement a service only once eases pain on the IT side because they don't have to continually update and maintain desktop BI applications.

With the BI SaaS solution there is more flexibly in obtaining the BI system on an as-needed basis. This allows the business to change 
to the modernised SaaS version of the required functionality once better technology is available (Li, Sedayao, et al. 2009). The SaaS vendor is responsible for keeping the latest software and configuration up to date and this removes the upgrade hassle from the business (Schadler 2008:2).

RightScale's (n.d.) customers felt that RightScale's BI SaaS products work incredibly well together as if it were one product. The customers also felt that the low cost barrier, without having to sacrifice performance or functionality was an advantage to them and that the BI SaaS solution delivering results on the first day of business.

Cloud computing allows for scaling up and down as capacity is required by the business and this is paid incrementally to the cloud computing vendor (Raths 2008). By making use of a BI SaaS solution this shifts the financial burden for the business from an upfront capital expense to an on-going operating expense. With this the business pays for the service as it is required, rather than a large upfront investment (Schadler 2008:4). With the cloudbased solution there is a lower financial risk to the business because the business only pays for what they use and can terminate the contract at any time. With on-premise solutions, the business needs to spend money upfront for hardware and software with an uncertain payoff (Schadler 2009:6).

The key challenge faced by businesses when making use of a SaaS BI service is that moving large data sets to the cloud could get costly and recommends shipping disks to the BI SaaS provider (All 2009). Another challenge for the business will be security and they recommend that sensitive data needs to remain on-premise and that the data that gets stored in the cloud be protected with encryption keys, SSL and certificates to store data securely in the cloud (All 2009).

All (2009) also found that established BI vendors only offered limited services in the cloud and that integrating on-premise data with cloud components is still a challenge.

\section{CONCLUSION}

Businesses that are agile and responsive to continuous change will be able to compete in a dynamic global economy. This will allow the business to be aware of market trends and evolving customer desires and enable the organisation to identify opportunities in good time and introduce new products to the market faster.

BI provides the business with an instrument to analyse data sources and derive valuable information from the transactional data sources that provide key insights into their customers. This allows the business with the ability to make informed and intelligent business decisions. The business can also make use of BI to monitor changes in behaviour in the environment that could trigger specific actions or customer engagements. Implementing and supporting BI in the business, however, requires an enormous capital layout and large volumes of data that needs to be analysed to identify trends in the business' data. It also requires enormous processing power, placing a great deal of pressure on the business resources.

Cloud computing services are described in this article as adjustable. Cloud computing provides scalability for peak periods and cost savings when usage is low. Clouds are designed to be dynamically scalable when more resources are required, so that software can be run on any available server with excess capacity. Cloud computing can be used by companies to address the issues that they are experiencing with their current onsite business intelligence solutions.

The data mining tools in the BI SaaS solution could provide the business with the relevant tools to make faster and more accurate strategic business decisions. By studying past behaviours, the business will have an enhanced understanding of the current situation and be better equipped to predict or influence change. This will allow the business to adopt the right strategy to achieve business objective (e.g. increased sales).

Making use of a BI SaaS solution is beneficial to the business but there is also some challenges that the business need to take into account before making use of this type of service. Moving large data sets to the cloud could get costly and security is also a concern when making use of cloud solutions. However, there is workarounds for these challenges and businesses need to do careful planning before moving to the cloud.

BI SaaS solution provides a more flexible model that aligns better with business objectives. This allows the business to evolve individual IT models, based strictly on business needs rather than on technology constraints. The business must find the right balance between the risks and rewards of computing in the cloud.

\section{REFERENCES}

7th Space, 2010, Leader in business analytics pioneers hosted delivery of powerful enterprise applications, viewed 28 June 2010, from http://7thspace.com/headlines/347763/leader_ in_business_analytics_pioneers_hosted_delivery_of_ powerful_enterprise_applications.html

All, A., 2009, 'Pros and Cons of Business Intelligence in the Cloud', IT Business Edge, viewed 13 September 2010, from http://www.itbusinessedge.com/cm/blogs/all/pros-andcons-of-business-intelligence-in-the-cloud/?cs=35060

Baker, K.A. \& Badamshina G.M., 2002, Chapter 5: Knowledge Management. Office of Science, Department of Energy, viewed 01 March 2005, from http://www.au.af.mil/au/awc/ awcgate/doe/benchmark/ch05.pdf

Bell, R. \& Todd, G., April 2007, Information Management Services: Overview of Services. Accenture, s.l.

Binney, D. \& Ishak, M., 2003, 'When E-business becomes K-business......will it be 'a natural act'?', in ACM Portal, viewed 17 July 2007, from http://portal.acm.org/citation.cfm?id=941 $609 \& \mathrm{dl}=\& \mathrm{coll}=\& \mathrm{CFID}=15151515 \& \mathrm{CFTOKEN}=6184618$

Chisholm, L. \& Human, A., 2006, 'Old Mutual's new SAP commissions system first of a kind in Africa, largest in the world', in ITWeb, viewed 17 July 2007, from http://www. itweb.co.za/office/sap/PressRelease.php?StoryID=160299

Chung ,W., Chen, H. \& Jay, F., 2002, Business Intelligence Explorer: A Knowledge Map Framework for Discovering Business Intelligence on the Web, Department of Management Information Systems, Eller College of Business and Public Administration, The University of Arizona, Tucson, AZ.

Collison, C. \& Parcell, G. 2001, Learning to Fly, Capstone Publishing Limited (A Wiley Company), London.

Competitive Intelligence, n.d. Competitive Intelligence, viewed 18 June 2010, from http://www.competitiveintelligence.com

Cooper, D.R. \& Schindler, P.S. 2003, Business Research Methods, 8th edn., McGraw-Hill/Irwin, Avenue of the Americas, New York.

Daugherty, P. \& Raj, S., 2008, 'Cloud Computing and Software as a Service', in Accenture, retrieved 29 April 2009, from http://www.accenture.com/cloud/

Department of Communications, Information Technology and the Arts (DCITA), 2003, Planning - Key issues to consider Knowledge management, e-Business guide, Australia, viewed 18 July 2007, from http://www.e-businessguide.gov.au/ planning/issues $/ \mathrm{km}$

EduCause, 2009, 7 Things you should know about virtualization, viewed 01 July 2010, from http://net.educause.edu/ir/ library/pdf/EST0904.pdf

Foster, I., Zhao, Y., Raicu, I. \& Lu, S., November 2008. Cloud Computing and Grid Computing 360-Degree Compared, Department of Computer Science, University of Chicago, Chicago. 
Imhoff, C., Galemmo, N. \& Geiger, J.G., 2003, Mastering Data Warehouse Design: Relational and Dimensional Techniques, John Wiley \& Sons, London.

LaValle, S., 2009, Business analytics and optimization for the intelligent enterprise, IBM Institute for Business Value, IBM Global Services, Route 100, Somers, New York.

Li, H., Sedayao, J., Hahn-Steichen, J., Jimison, E., Spence, C. \& Chahal, S., 2009, Developing an Enterprise Cloud Computing Strategy. Intel Information Technology, Computer Manufacturing, Cloud Computing, USA.

Liebowitz, J., 2006, Strategic Intelligence: Business Intelligence, Competitive Intelligence, and Knowledge Management, Auerbach Publications, London.

Maini, N., 2010, Leveraging Siebel Analytics to Enhance Sales in Pharmaceutical Industry. Accenture, s.l.

Microsoft, 2010, Forecast: Improved economy in the cloud, viewed 01 July 2010, from www.slideshare.net/govloop/cloudservices-whitepaper

Mundy, J., Thornthwaite, W. \& Kimball, R., 2006, Mastering Data Warehouse Design: Relational and Dimensional Techniques, John Wiley \& Sons, London.

Prakash, N., n.d., SaaS to boost business analytics mart, viewed 28 June 2010, from http://www.expresscomputeronline. com/20100621/coverstory01.shtml.

Raths, D., 2008, Cloud Computing: Public-Sector Opportunities Emerge, viewed 03 May 2009, from http://www.govtech. com/gt/387269

Schadler, T., 2008, Talking To Your CFO About Cloud Computing, Forrester Research, Inc., USA.
Schadler, T., 2009, Should Your Email Live In The Cloud? A Comparative Cost Analysis, Forrester Research, Inc., USA.

Sharp, S., 2009, Competitive Intelligence Advantage: How to Minimize Risk, Avoid Surprises, and Grow Your Business in a Changing World, John Wiley \& Sons, London.

Sullivan, T., 2008, 'BI steps into the cloud' in InfoWorld, viewed 08 September 2010, from http://www.infoworld.com/d/ cloud-computing/bi-steps-cloud-085

Swaminathan, K.S, Daugherty, P. \& Tobolski, J.F., 2009, 'What the Enterprise Needs to Know about Cloud Computing', Accenture Technology Labs, viewed 27 April 2009, from www. accenture.com/accenturetechlabs/

Papaioannou, T., n.d., 'Cloud Computing and your Data Warehouse' in Teradata Labs, viewed 30 June 2010, from http://www.slideshare.net/drluckyspin/cloud-computingand-your-data-warehouse

RightScale, n.d., Business intelligence for the cloud software stack helps gaming sites quickly adapt to evolving customer needs, viewed 30 August 2010, from http://www.RightScale.com/BI

Ubuntu, n.d., Private Cloud, viewed 30 June 2010, from http:// www.ubuntu.com/cloud/private

Velte, A.T., Velte, T.J. \& Elsenpeter, R., 2010, Cloud Computing: A Practical Approach, McGraw-Hill/Osborne, San Francisco.

Verma, K. \& Negm, W., 2008, Cloud /Web Scale Computing: Evolving Software Architectures. Accenture Technology Vision, viewed 27 April 2008, from http://www.accenture.com/cloud/

Williams, S. \& Williams, N., 2007, The Profit Impact of Business Intelligence, Morgan Kaufmann Publishers, Massachusetts. 